\title{
Analysis of Acceptance of Toddler Nutrition Monitoring Information System using Technology Acceptance Model (TAM)
}

\author{
Mukhammad Fakhir Rizal \\ Master of Information System, \\ School of Post Graduate, \\ Diponegoro University, \\ Indonesia
}

\author{
Aris Puji Widodo \\ Department of Informatics, \\ Faculty of Science and \\ Mathematics, \\ Diponegoro University, Indonesia
}

\author{
Oky Dwi Nurhayati \\ Department of Computer \\ Engineering, \\ Faculty of Engineering, \\ Diponegoro University, \\ Indonesia
}

\begin{abstract}
This research is a quantitative research that has a goal to measure the level of user acceptance of the Mozita Application. Mozita application is an application used by midwives (cadres) to carry out the process of recording and reporting the nutritional status of toddler in the local health center area. In addition to information on the nutritional status of toddler, the calculation using the Z-Score formula, the Mozita application can present information used by related agencies for the purpose of monitoring and decision making in terms of health policy based on data on nutritional status of toddler. To be able to increase the use of the Mozita application, it is necessary to provide feedback from the user. TAM (Technology Acceptance Model) is a model chosen to analyze and understand the factors that influence the acceptance of the use of the Mozita Application, user feedback is done by utilizing the USE Questionnaire. This study used 96 respondents who were randomly selected from cadres, midwives, employees at the village level, district level, city level, and people who worked in the health department in the city area of Semarang. The technique used to measure the level of acceptance is done by providing an explanation and guidelines for using the Mozita application before the respondent fills in the questionnaire using a Likert scale. The questionnaire used is equipped with in-depth interviews for question items whose Likert scale value is less than equal to 3 . The indepth interview aims to provide a focus on improving the Mozita application interface to be able to suit the needs of users. Based on testing and data analysis results, it was concluded that the 5 hypotheses $\mathrm{H} 1, \mathrm{H} 2, \mathrm{H} 3, \mathrm{H} 4$, and $\mathrm{H} 5$ adopted from the TAM model had a positive effect on the strength of the relationship (correlation) between strong variables, except the relationship between the Perceived Usefulness variable against Attitude Toward Using (H2).
\end{abstract}

\section{Keywords}

TAM (Technology Acceptance Model), Toddler Nutrition, ZScore, USE Questionnaire

\section{INTRODUCTION}

Nutrition in infants is influenced by socioeconomic factors and socio-cultural backgrounds related to diet and nutrition. Poor nutrition in the early stages of growth results in irreversible physical, mental and brain growth and development disorders. A measure of success in fulfilling nutrition is nutritional status. The nutritional status of children under five reflects the level of development and well-being of people in a country and is related to the health status of children in the future [1].

Malnutrition generally refers to the condition of malnutrition, poor nutrition and over nutrition. This condition is one of the leading causes of mortality and morbidity in children under five in developing countries, as many as $54 \%$ or 10.8 million children die from malnutrition [2]. Malnutrition in infants has an impact on decreasing the immune system so that it is susceptible to infectious diseases. Infectious diseases such as diarrhea, pneumonia, malaria, measles or measless and AIDS are known to cause the most deaths in children under five with malnutrition.

According to WHO (2016) the number of malnourished sufferers in the world reaches 104 million children and the state of undernutrition is still the cause of one third of all causes of child death worldwide. South Asia is the region with the highest prevalence of malnutrition in the world, which is 46\% then sub-Saharan Africa 28\%, Latin America 7\% and the lowest is in Central, Eastern Europe, and the Commonwealth of Independent States (CEE/ CIS) by 5\%. UNICEF reports that as many as 167 million pre-school-aged children in the world who suffer from underweight are mostly in South Asia [3].

Data compiled by the Ministry of Health of the Health Research and Development Agency in 2018 shows malnutrition and malnutrition among children under five at 17.7\%. Many effects result from malnutrition during childhood such as slower physical growth, delay in motor development, lower IQ of adequately nourished children (later linked to lower educational attainment).

Nutritional status assessment is basically a process of checking a person's nutritional state by collecting important data, both objective (such as body weight, lean body mass, etc.) and subjective, to then be compared with existing calculation rules. Nutritional status assessment can be done directly and indirectly, direct assessment includes anthropometry, biochemistry, clinical and biophysical, while indirect assessment includes surveys of food consumption, vital statistics, and ecological factors [4]. However, in this study only using anthropometry, where anthropometry is easy to use and relatively inexpensive to implement in the smallest unit of health agencies in Indonesia, namely posyandu, a noninvasive measurement tool (does not cause trauma to the person being measured). Commonly used measures are height (or length), weight, upper arm circumference, and age [5].

The relatively high number of malnutrition among children under five, the need for workers who are able to deal with 
cases of malnutrition quickly, accurately and professionally, followed by the preparation of adequate facilities and infrastructure. Regarding the speed and accuracy of the actions that must be taken, a Health Information System that connects the community, relevant stakeholders, and medical personnel is needed to accommodate them. On the other hand, improving health and nutritional status is often associated with increasing long-term outcomes, including decreasing the likelihood of chronic illness, increasing educational attainment, and producing qualified human resources to compete in the labor market [6].

Information systems can be said to be effective when two main questions are asked, namely the scale of the use of features/ functions by users of all that is provided, then the second is how quickly the user adapts when there are changes in the appearance, features, or menus of the previous system [7]. That factor can indicate an individual's decision to use a system or leave it.

With the TAM (Technology Acceptance Model) this study was made to find out whether from the user's side the use of the Toddler Nutrition Information System can be accepted as a system that can help the community in tackling malnutrition in infants or not.

\section{REVIEW OF RELATED WORKS}

In a study that made an application called sisfor_bidanku to facilitate midwives in detecting growth and development of infants based on anthropometry, testing was conducted to determine their comfort in using the application. The study was conducted in August-September 2019 in the work area of the Posalandu at the Campalagian Puskesmas in Polewali Mandar, West Sulawesi, on the basis of an experimental study and the sample of research was a midwife in charge of monitoring growth and development in the posyandu area of 20 people. Data shows that midwives who have the perception that midwife application is very easy are ten people (25\%), although there are still four people $(10 \%)$ who state that conventional applications are also very easy. Conclusion Midwives have the perception that it is easy to use my sisfor_bid application, but the conventional method is also relatively easy [8].

Research published in Accident Analysis \& Prevention entitled "Assessing the utility of TAM, TPB, and UTAUT for advanced driver assistance systems" discusses driver acceptance of an Advanced Driver Assistance Systems (ADAS) using the Technology Acceptance Model (TAM), Theory of Planned Behavior (TPB), and Unified Theory of Acceptance and Use of Technology (UTAUT) result that using TAM is the best, followed by TPB and UTAUT, where TAM is one of the models built to analyze and understand the factors that affect the acceptance of use computer technology [9].

\section{BACKGROUND STUDY}

\subsection{Technology Acceptance Model (TAM)}

Technology Acceptance Model (TAM) is one of the models that was built to analyze and understand the factors that influence the acceptance of the use of computer technology which was first introduced by Fred Davis in 1986. TAM is the result of the development of Theory of Reasoned Action (TRA), which first developed by Fishbein and Ajzen in 1980. TAM aims to explain and estimate user acceptance of an information system, TAM explains the causal relationship between belief (about the benefits of an information system and ease of use) and behavior, goals/ needs, and the actual use of users of an information system.

According to Davis the behavior of using IT is preceded by a perception of the benefits (perceived of usefulness) and perceptions about the ease of use of IT (ease of use), then defines the perception of usefulness (perceived of usefulness) based on the definition of the word useful that is capable of being used advantageously, or can be used for a profitable purpose. Perception of usability is the benefit that individuals believe can be obtained when using IT. Potential users believe that certain applications are useful, at the same time believe that this system is not too difficult to use. That is, in addition to the benefits or usefulness, the application of information technology systems will also be influenced by the perceived ease of use (perceived ease of use). Therefore Davis added the two components to the TAM model. In simple terms TAM is shown in Figure 1.

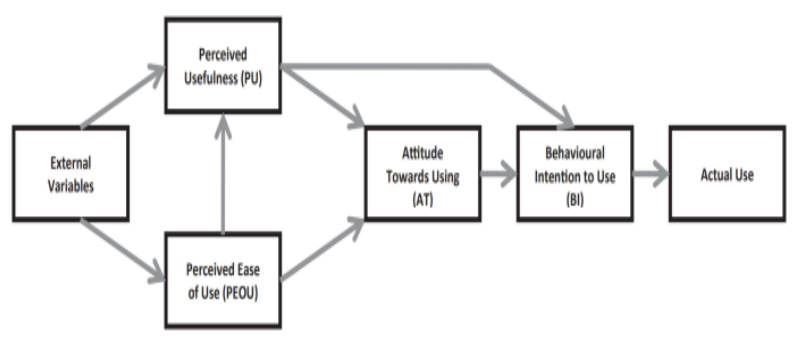

Fig 1: Technology Acceptance Model [10]

The two main variables in a TAM study are the independent (independent) and the dependent (dependent) variables, while the independent variables are PEOU and PU, while the dependent variables are ATU, and BI, which ultimately affect the use (AU) of a system, however This dependent variable does not always appear in every model at the same time.

\section{METHOD}

The material used in this study was a questionnaire which would later be distributed to respondents, using USE (Usefulness, Satisfaction, Ease of use) Questionnaire. The USE Questionnaire has the highest proportion of measurements in the experience domain compared to other questionnaires [11]. The tool used is a set of computers with PHP programming language with CodeIgniter framework and MySQL database.

Based on the TAM model that has been explained on the basis of theory, not all attributes will be used as material in this study, the following TAM concept will be applied as shown in Figure 2.

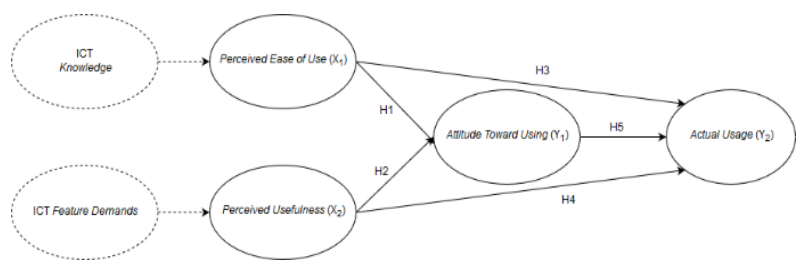

Fig 2: TAM Research Framework [12]

Based on Figure 2 shows that the independent variables (Perceived Ease of Use and Perceived Usefulness) have an influence on the dependent variable (Attitude Toward Using and Actual Usage). In this research, the extent to which the independent variable is influenced by external variables, namely ICT knowledge related to PEoU, and ICT feature demands related to PU. In addition, Attitude Toward Using also has a direct influence on Actual Usage. This research was 
conducted to find out about the effect of Perceived Ease of Use and Perceived Usefulness on the use of a nutrition monitoring system for toddlers for health workers (posyandu cadres or midwives), the community (in this case parents of toddlers whose nutritional status will be seen), and related stakeholders (government apparatus, and health services) which will be implemented in the Semarang City area. From the research framework that has been made, the following hypotheses can be derived:

H1: Perceived ease of use has a positive effect on attitude toward using Toddler Nutrition Monitoring System.

H2: Perceived usefulness has a positive effect on attitude toward using Toddler Nutrition Monitoring System.

H3: Perceived ease of use has a positive effect on the actual usage of the Toddler Nutrition Monitoring System.

H4: Perceived usefulness has a positive effect on the actual usage of the Toddler Nutrition Monitoring System.

H5: Attitude toward using positively influences the actual usage of the Toddler Nutrition Monitoring System.

This population can be used to refer to all members of an area/ place that are targeted as research (subjects). The population in this study is limited to the area of Semarang City that targets midwives/ cadres in Posyandu, Sub District's IT Division, District's IT Division, IT Staff in Puskesmas, and the Semarang City Government IT Division, totaling 2,036 people, with details in Table 1.

Table 1. Details of population coverage in the study

\begin{tabular}{|c|c|c|}
\hline Subject & Description & Total \\
\hline $\begin{array}{c}\text { Semarang City } \\
\text { Government IT } \\
\text { Division - } \\
\text { Person }\end{array}$ & - & 5 Person \\
\hline $\begin{array}{c}\text { District's IT } \\
\text { Division - } \\
\text { Person }\end{array}$ & 16 District & 32 Person \\
\hline $\begin{array}{c}\text { Sub District's IT } \\
\text { Division - } \\
\text { Person }\end{array}$ & 177 Sub District & 177 Person \\
\hline $\begin{array}{c}\text { Puskesmas - 1 } \\
\text { Person }\end{array}$ & 37 Puskesmas & 37 Person \\
\hline $\begin{array}{c}\text { Midwives/ Cadres } \\
\text { in Posyandu - 5 } \\
\text { Person }\end{array}$ & 357 Posyandu & 1.785 Person \\
\hline \multicolumn{2}{|c|}{ Total } & 2.036 Person \\
\hline
\end{tabular}

The sample is part of the selected population members, in this study in determining the research sample using the Slovin formula, namely [13]:

$n=N /\left(1+N . e^{2}\right)$

Where:

$\mathrm{n}$ : Minimum sample size

N: Population size

e: The desired error level

If the desired error rate is $10 \%$, and $\mathrm{N}=2,036$, the minimum number of samples to be investigated is as follows:

$\boldsymbol{n}=2,036 /\left(1+2,036(0,10)^{2}\right)$

\section{$=95,31835205992509$ rounded to 96}

From the calculations carried out above, it can be seen that the minimum number of samples in this study was 96 people.

The sampling technique in this study uses nonprobability sampling. Nonprobability sampling is a technique used for sampling where each member of the population does not have the same opportunity or opportunity as a sample [14], based on certain criteria. The criteria are as follows:

a. Proficient in operating computers.

b. If the first criterion is not met, the second criterion is the person who has and operates a computer and has browsed several times via a PC / Laptop.

\section{RESULT AND ANALYSIS}

\subsection{Result}

In general, the Mozita application can be seen in Figure 3 which is an athropometric data parameter entry feature, and Figure 4 is a notification model if abnormal toddler problems occur according to the anthropometric table.

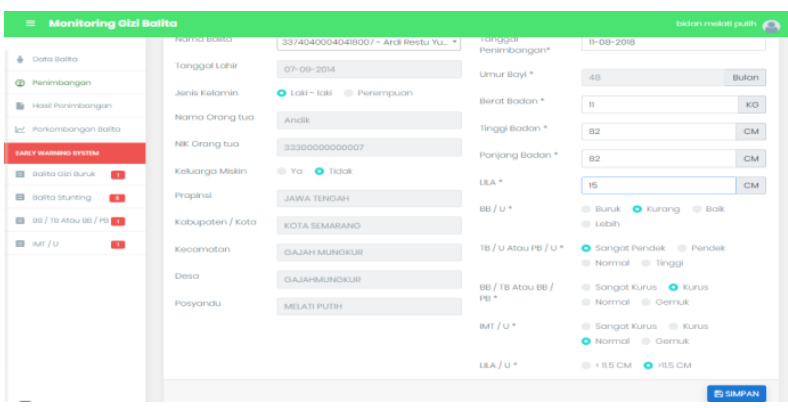

Fig 3: Parameter Data Entry

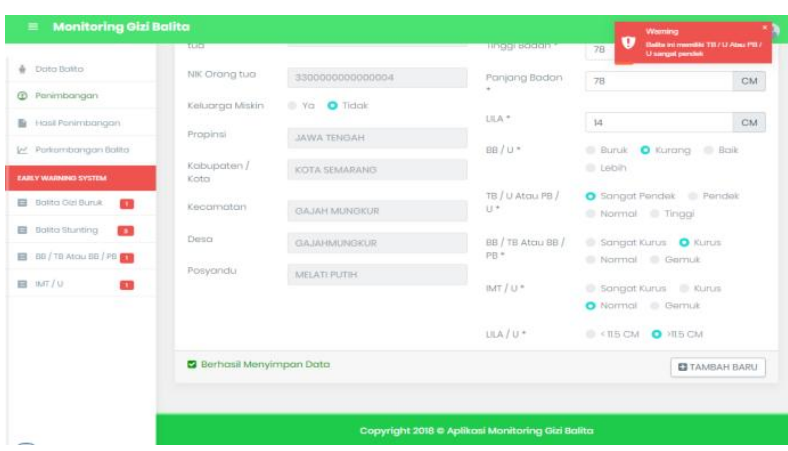

Fig 4: Early Warning System Form

Research data were collected by distributing questionnaires both directly and online using the Google Form application with a total of 127 respondents, with 31 initial respondents used as validity and reliability test data from the questionnaire. Testing is done with the help of SPSS analysis tools.

After the validity and reliability results obtained from the first questionnaire will then be distributed back to the second respondent with a total of 96 respondents in accordance with the sample calculations described in the previous chapter.

The following is the data recap of the results of research that has been done. 


\subsubsection{Respondents based on gender}

The respondents selected by sex consisted of two groups namely men and women. To find out the percentage of sex clearly, can be seen in Table 2.

Table 2. Respondents by sex

\begin{tabular}{|c|c|c|c|}
\hline No & Gender & Total & Percentage \\
\hline 1. & Male & 60 & $47.24 \%$ \\
\hline 2. & Female & 67 & $52.76 \%$ \\
\hline \multicolumn{2}{|c|}{ Total } & 127 & $100 \%$ \\
\hline
\end{tabular}

Based on the Table 2, it can be seen that the percentage of respondents who have the most number by sex are women as many as 67 respondents or $52.76 \%$ of the total respondents selected. While respondents with male gender are 60 respondents or $47.24 \%$ of the total respondents selected.

\subsubsection{Respondents by age}

Characteristics of respondents by age are classified into 4 groups. To find out the percentage of age, it can be seen clearly in Table 3 .

Table 3. Respondents by age

\begin{tabular}{|c|c|c|c|}
\hline No & Age & Total & Percentage \\
\hline 1. & $20-30$ Years & 69 & $54.33 \%$ \\
\hline 2. & $31-40$ Years & 27 & $21.26 \%$ \\
\hline 3. & $41-50$ Year & 19 & $14.96 \%$ \\
\hline 4. & More than 50 Years & 12 & $129.45 \%$ \\
\hline \multicolumn{2}{|c|}{ Total } & 127 & $100 \%$ \\
\hline
\end{tabular}

From Table 3, it can be seen that the highest percentage of respondents based on age is in the range of 20-30 years with 69 respondents or $54.33 \%$, followed by respondents aged 31 40 years with 27 respondents or $21.26 \%$, then followed by respondents aged 41-50 years with a total of 19 respondents or $14.96 \%$ and for the smallest percentage of respondents were respondents who were in the range of more than 50 years with a total of 12 respondents or $9.45 \%$.

\subsection{Analysis}

The analysis in this study includes the validity test, reliability test, and hypothesis testing, along with the elaboration of each test.

\subsubsection{Validity Test}

5.2.1.1 Perceived Ease of Use Variable $\left(X_{1}\right)$

Table 4. Test results for the validity of the Perceived Ease of Use $\left(\mathrm{X}_{1}\right)$ variable

\begin{tabular}{|c|c|c|c|}
\hline Statement & $\mathrm{r}$ count & $\mathrm{r}$ table $(5 \% ; \mathrm{N}=31)$ & Status \\
\hline PEOU1 & 0,545 & 0,355 & Valid \\
\hline PEOU2 & 0,658 & 0,355 & Valid \\
\hline PEOU3 & 0,480 & 0,355 & Valid \\
\hline PEOU4 & 0,697 & 0,355 & Valid \\
\hline PEOU5 & 0,609 & 0,355 & Valid \\
\hline
\end{tabular}

\begin{tabular}{|c|c|c|c|}
\hline PEOU6 & 0,382 & 0,355 & Valid \\
\hline PEOU7 & 0,573 & 0,355 & Valid \\
\hline PEOU8 & 0,752 & 0,355 & Valid \\
\hline PEOU9 & 0,764 & 0,355 & Valid \\
\hline PEOU10 & 0,486 & 0,355 & Valid \\
\hline PEOU11 & 0,785 & 0,355 & Valid \\
\hline
\end{tabular}

From Table 4 it can be seen that the granular Perceived Ease of Use variable statement is declared valid. This can be known $r$ count $>0.355$. Figures 0.355 are $r$ tables obtained from $\mathrm{r}$ tables of product moment at the significant level $(\mathrm{a})=$ $5 \%$ and $\mathrm{N}=31$.

\subsubsection{Perceived Usefulness Variable $\left(X_{2}\right)$}

Table 5. Test results for the validity of Perceived Usefulness $\left(\mathrm{X}_{2}\right)$ variables

\begin{tabular}{|c|c|c|c|}
\hline Statement & $\mathrm{r}$ count & $\mathrm{r}$ table $(5 \% ; \mathrm{N}=31)$ & Status \\
\hline PU1 & 0,466 & 0,355 & Valid \\
\hline PU2 & 0,676 & 0,355 & Valid \\
\hline PU3 & 0,589 & 0,355 & Valid \\
\hline PU4 & 0,529 & 0,355 & Valid \\
\hline PU5 & 0,585 & 0,355 & Valid \\
\hline PU6 & 0,566 & 0,355 & Valid \\
\hline PU7 & 0,837 & 0,355 & Valid \\
\hline PU8 & 0,610 & 0,355 & Valid \\
\hline
\end{tabular}

From Table 5 it can be seen that the granular Perceived Ease of Use variable statement is declared valid. This can be known $\mathrm{r}$ count $>0.355$. Figures 0.355 are $r$ tables obtained from $\mathrm{r}$ tables of product moment at the significant level $(\mathrm{a})=$ $5 \%$ and $\mathrm{N}=31$.

\subsubsection{Attitude Toward Using Variable $\left(Y_{1}\right)$}

Table 6. Test results for the validity of the Attitude Toward Using variable $\left(\mathbf{Y}_{1}\right)$

\begin{tabular}{|c|c|c|c|}
\hline Statement & $\mathrm{r}$ count & $\mathrm{r}$ table $(5 \% ; \mathrm{N}=31)$ & Status \\
\hline ATT1 & 0,815 & 0,355 & Valid \\
\hline ATT2 & 0,885 & 0,355 & Valid \\
\hline ATT3 & 0,876 & 0,355 & Valid \\
\hline ATT4 & 0,772 & 0,355 & Valid \\
\hline
\end{tabular}

From Table 6 above it can be seen that the details of the Attitude Toward Using variable statement are valid. This can be seen $\mathrm{r}$ count $>0.355$. Figures 0.355 is the table obtained from the table of product moment $\mathrm{r}$ at the significant level (a) $=5 \%$ and $\mathrm{N}=31$. 


\subsubsection{Actual Usage Variable $\left(Y_{2}\right)$}

Table 7. Test results for the validity of the Actual Usage Variable $\left(\mathbf{Y}_{2}\right)$

\begin{tabular}{|c|c|c|c|}
\hline Statement & r count & $\mathrm{r}$ table $(5 \% ; \mathrm{N}=31)$ & Status \\
\hline AU1 & 0,646 & 0,355 & Valid \\
\hline AU2 & 0,606 & 0,355 & Valid \\
\hline AU3 & 0,745 & 0,355 & Valid \\
\hline AU4 & 0,672 & 0,355 & Valid \\
\hline AU5 & 0,797 & 0,355 & Valid \\
\hline AU6 & 0,655 & 0,355 & Valid \\
\hline AU7 & 0,743 & 0,355 & Valid \\
\hline
\end{tabular}

From Table 7 it can be seen that the details of the Actual Usage statement are valid. This can be seen $r$ count $>0.355$. Figures 0.355 is the table obtained from the table of product moment $\mathrm{r}$ at the significant level $(\mathrm{a})=5 \%$ and $\mathrm{N}=31$.

\subsubsection{Reliability Test}

After testing the validity of each variable, reliability testing can then be performed. The results of the reliability analysis can be seen in the SPSS program output and is shown by the value of alpha (a). Decision making reliability of the answers to a variable is determined by the assumption that if the Cronbach alpha value $>0.7$ then the statement of the variables studied are reliable. The reliability test results are shown in Table 8.

Table 8. Reliability test results

\begin{tabular}{|c|c|c|c|}
\hline Variable & R Alpha & Alpha Cronbach & Status \\
\hline PEOU $\left(\mathrm{X}_{1}\right)$ & 0,835 & 0,7 & Reliabel \\
\hline PU $\left(\mathrm{X}_{2}\right)$ & 0,749 & 0,7 & Reliabel \\
\hline ATT $\left(\mathrm{Y}_{1}\right)$ & 0,857 & 0,7 & Reliabel \\
\hline AU $\left(\mathrm{Y}_{2}\right)$ & 0,817 & 0,7 & Reliabel \\
\hline
\end{tabular}

Based on Table 8 it can be shown that all variable values are declared reliable with values above 0.7 .

\subsubsection{Hypothesis Testing}

Hypothesis testing is an empirical proof method to confirm or reject an initial hypothesis (it can be called an opinion or an assumption) using certain sample data [15]. There are several stages in order to be able to get a conclusion on the initial hypothesis, following the stages.

Normality test aims to test whether the data used in research is normally distributed or not. Normality test is one part of the test requirements for data analysis or classic assumption test, meaning that before conduct statistical analysis to test the hypothesis in this case is a regression analysis, then the research data must be tested for distribution.

Kolmogorov-Smirnov test is one of the formulas of normality testing, the basic concept is to compare the data distribution (which will be tested for normality) with the standard normal distribution. The main objective is to test whether the sample value comes from a population with an expected theoretical distribution or expected, in this case, a normal distribution [15]. The following results of the Kolmogorov-Smirnov normality test are shown in Table 9.

Table 9. Descriptive tables and results of the KolmogorovSmirnov normality test

\begin{tabular}{|c|c|c|c|c|}
\hline Variabel & Mean \pm SD & $\begin{array}{c}\text { Median } \\
(\mathbf{m i n}-\mathbf{m a x})\end{array}$ & $\mathbf{p}$ & Status \\
\hline $\begin{array}{c}\text { Perceived } \\
\text { Ease of } \\
\text { Use }\left(\mathrm{X}_{1}\right)\end{array}$ & $42,29 \pm 5,03$ & $43(32-55)$ & 0,199 & Normal \\
\hline $\begin{array}{c}\text { Percieved } \\
\text { Usefulness } \\
\left(\mathrm{X}_{2}\right)\end{array}$ & $32,67 \pm 3,61$ & $32(24-40)$ & 0,000 & $\begin{array}{c}\text { Not } \\
\text { normal }\end{array}$ \\
\hline $\begin{array}{c}\text { Attitude } \\
\text { Toward } \\
\text { Using } \\
\left(\mathrm{Y}_{1}\right)\end{array}$ & $16,16 \pm 2,17$ & $16(8-20)$ & 0,000 & $\begin{array}{c}\text { Not } \\
\text { normal }\end{array}$ \\
\hline $\begin{array}{c}\text { Actual } \\
\text { Usage } \\
\left(\mathrm{Y}_{2}\right)\end{array}$ & $27,28 \pm 3,35$ & $28(21-35)$ & 0,003 & $\begin{array}{c}\text { Not } \\
\text { normal }\end{array}$ \\
\hline
\end{tabular}

From the results shown in Table 4.18, a variable is said to be normal when the $\mathrm{p}$ value is more than the pre-determined significance level of 0.05 , thus there are 1 normal variables (X1) and 3 abnormal variables (X2, Y1, Y2). When after the normality test there is abnormal data, it is transferred to nonparametric statistics.

Spearman rank correlation analysis can be used to measure the level of closeness of the relationship between two independent / random variables that are ordinal scale (nonparametric statistics), in this correlation analysis there is no need to assume a linear relationship (linearity test) between research variables. This method was proposed by Carl Spearman in 1904. If the research data use a Likert scale, the distance used must be the same and the research data do not have to be normally distributed [16].

In correlation analysis there is no term independent variable (X) or the dependent variable (Y). Thus, it can be interpreted that the two variables correlated (linked) are independent from one another, the meaning is that each variable stands alone and does not depend on each other. Suppose a variables $X$ and $\mathrm{Y}$, then the relationship between variables $\mathrm{X}$ and $\mathrm{Y}$ is the same as the relationship between variables $Y$ and $X$.

\section{Criteria for the degree of correlation strength}

In determining the level of strength of the relationship between variables, the correlation coefficient value is needed which is the result of SPSS output, provided that:

- Correlation coefficient value of $0.00-0.25=$ very weak relationship

- Correlation coefficient values of $0.26-0.50=$ medium relationship

- Correlation coefficient values of $0.51-0.75=$ strong relationship

- Correlation coefficient value of $0.76-0.99=$ very strong relationship

- Correlation coefficient value of $1.00=$ perfect relationship 


\section{Correlation direction criteria}

The direction of the correlation is seen in the number of correlation coefficients as well as the degree of correlation strength. The magnitude of the value of the correlation coefficient lies between +1 to -1 . If the correlation coefficient is positive, then the relationship between the two variables is said to be the same. The purpose of this unidirectional relationship is that if the variable $\mathrm{X}$ increases, the variable $\mathrm{Y}$ will also increase. Conversely, if the correlation coefficient is negative then the relationship between the two variables is not unidirectional. Not in the same direction, if variable $X$ increases, then Y variable will decrease.

\section{Correlation significance criteria}

The strength and direction of the correlation (relationship) will have meaning if the relationship between these variables is significant. It said there was a significant relationship, if the Sig. (2-tailed) calculation results are smaller than the value of 0.05 or 0.01 . Meanwhile, if the value of Sig. (2-tailed) is greater than 0.05 or 0.01 , then the relationship between these variables can be said to be insignificant or insignificant.

Following are the test details, starting from the Spearman rank correlation output shown in Figure 3.

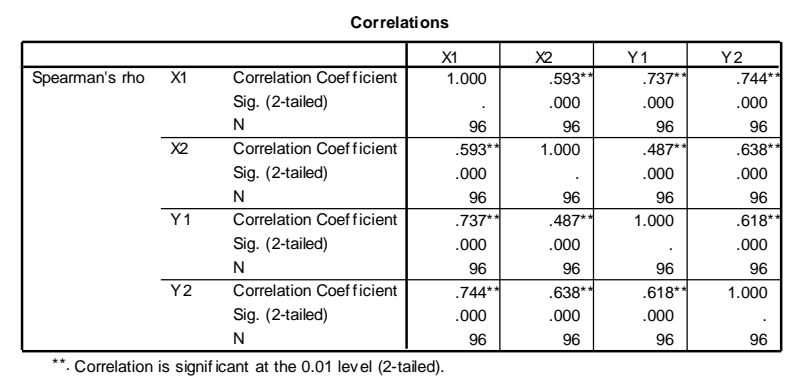

Fig. 3: Spearman rank correlation output

The spearman correlation test between the Perceived Ease of Use $\left(\mathrm{X}_{1}\right)$ variable and the Percieved Usefulness $\left(\mathrm{X}_{2}\right)$ variable to the Attitude Toward Using $\left(\mathrm{Y}_{1}\right)$ variable is shown in Table 10 .

Table 10. Table of Spearman Correlation Test Results Perceived Ease of Use $\left(X_{1}\right)$ and Percieved Usefulness $\left(X_{2}\right)$ to Attitude Toward Using $\left(Y_{1}\right)$

\begin{tabular}{|c|c|c|c|}
\hline \multirow{2}{*}{ Variable } & \multicolumn{2}{|c|}{$\begin{array}{c}\text { Attitude Toward Using } \\
\left(\mathrm{Y}_{1}\right)\end{array}$} & Description \\
\cline { 2 - 4 } & $\mathrm{p}$ & $\mathrm{r}$ & \\
\hline $\begin{array}{c}\text { Perceived } \\
\text { Ease of Use } \\
\left(\mathrm{X}_{1}\right)\end{array}$ & 0,000 & 0,737 & $\begin{array}{c}\text { Significant, } \\
\text { positive, strong }\end{array}$ \\
\hline $\begin{array}{c}\text { Percieved } \\
\text { Usefulness } \\
\left(\mathrm{X}_{2}\right)\end{array}$ & 0,000 & 0,487 & $\begin{array}{c}\text { Significant, } \\
\text { positive, } \\
\text { moderate }\end{array}$ \\
\hline
\end{tabular}

Based on Figure 3 and Table 10 can be read that the level of strength of the relationship (correlation) between the variable Perceived Ease of Use with Attitude Toward Using is 0.737 or strong. An asterisk (**) means that the correlation is significant at a significance level of 0.01 . The correlation coefficient number on the results above is positive, which is 0.737 , so that the relationship between the two variables is one-way (type of unidirectional relationship), thus it can be interpreted that someone has a high perception of ease in using the Mozita application, the desire to use the application is higher

Based on Figure 3 and Table 10 can be read that the level of strength of the relationship (correlation) between the Percieved Usefulness variable with Attitude Toward Using is equal to 0.487 or moderate. An asterisk (**) means that the correlation is significant at a significance level of 0.01 . The correlation coefficient number on the results above is positive, which is 0.487 , so the relationship between the two variables is one-way (type of one-way relationship), thus it can be interpreted that someone has a high perception of the benefits obtained when using the Mozita application, the desire to use the application the higher.

Table 11. Spearman correlation test results table Perceived Ease of Use $\left(X_{1}\right)$, Percieved Usefulness $\left(X_{2}\right)$ and Attitude Toward Using ( $\left.\mathbf{Y}_{1}\right)$ against Actual Usage $\left(\mathbf{Y}_{2}\right)$

\begin{tabular}{|c|c|c|c|}
\hline \multirow{2}{*}{ Variable } & \multicolumn{2}{|c|}{ Actual Usage $\left(\mathrm{Y}_{2}\right)$} & \multirow{2}{*}{ Description } \\
\hline & $\mathrm{p}$ & $\mathrm{r}$ & \\
\hline $\begin{array}{c}\text { Perceived } \\
\text { Ease of Use } \\
\quad\left(\mathrm{X}_{1}\right)\end{array}$ & 0,000 & 0,744 & $\begin{array}{c}\text { Significant, } \\
\text { positive, strong }\end{array}$ \\
\hline $\begin{array}{c}\text { Percieved } \\
\text { Usefulness } \\
\quad\left(\mathrm{X}_{2}\right)\end{array}$ & 0,000 & 0,638 & $\begin{array}{c}\text { Significant, } \\
\text { positive, strong }\end{array}$ \\
\hline $\begin{array}{c}\text { Attitude } \\
\text { Toward Using } \\
\left(\mathrm{Y}_{1}\right)\end{array}$ & 0,000 & 0,618 & $\begin{array}{l}\text { Significant, } \\
\text { positive, strong }\end{array}$ \\
\hline
\end{tabular}

Based on Figure 3 and Table 11 can be read that the level of strength of the relationship (correlation) between the variable Perceived Ease of Use with Actual Usage is equal to 0.744 or strong. An asterisk (**) means that the correlation is significant at a significance level of 0.01. Correlation coefficient number on the results above is positive, that is 0.744 , so that the relationship between the two variables is one-way (the type of unidirectional relationship), thus it can be interpreted that someone has a high perception of ease in using the Mozita application, the attitude towards the use of the application is higher .

Based on Figure 3 and Table 11 can be read that the level of strength of the relationship (correlation) between the Percieved Usefulness variable with Actual Usage is equal to 0.638 or strong. An asterisk (**) means that the correlation is significant at a significance level of 0.01 . The correlation coefficient number on the results above is positive, which is 0.638 , so that the relationship between the two variables is unidirectional (type of unidirectional relationship), thus it can be interpreted that someone has a high perception of the benefits obtained when using the Mozita application, the attitude towards the use of the application the higher.

Based on Figure 3 and Table 11 can be read that the level of strength of the relationship (correlation) between the Attitude Toward Using variable with Actual Usage is equal to 0.618 or strong. An asterisk (**) means that the correlation is significant at a significance level of 0.01 . The correlation coefficient number on the results above is positive, which is 0.618 , so that the relationship between the two variables is one-way (type of one-way relationship), thus it can be interpreted that someone has a desire to use a high 
application, the attitude towards the use of the application is higher.

Based on a series of tests, the hypothesis presented in chapter 3 can be summarized as follows:

1. Perceived Ease of Use Hypothesis has a positive effect on Attitude Toward Using Toddler Nutrition Monitoring System

Assume,

$\mathrm{H}_{0}=$ Perceived Ease of Use negatively influences Attitude Toward Using Toddler Nutrition Monitoring System.

$\mathrm{H}_{1}=$ Perceived Ease of Use has a positive effect on Attitude Toward Using Toddler Nutrition Monitoring System.

In Table 10 the test statistic (p) is $0.00, \mathrm{H}_{0}$ is rejected if the $\mathrm{p}$ value is less than the 0.05 significance level, so the conclusion of the Perceived Ease of Use hypothesis has a positive effect on Attitude Toward Using Toddler Nutrition Monitoring System.

2. Perceived Usefulness Hypothesis has a positive effect on Attitude Toward Using Toddler Nutrition Monitoring System

Assume,

$\mathrm{H}_{0}=$ Perceived Usefulness has a negative effect on Attitude Toward Using Toddler Nutrition Monitoring System.

$\mathrm{H}_{1}=$ Perceived Usefulness has a positive effect on Attitude Toward Using Toddler Nutrition Monitoring System.

In Table 10 the test statistic (p) of $0.00, \mathrm{H}_{0}$ is rejected if the $\mathrm{p}$ value is less than the significance level of 0.05 then the conclusion of the Perceived Usefulness hypothesis has a positive effect on Attitude Toward Using the Toddler Nutrition Monitoring System.

3. The Perceived Ease of Use Hypothesis has a positive effect on the Actual Usage of the Toddler Nutrition Monitoring System

Assume,

$\mathrm{H}_{0}=$ Perceived Ease of Use negatively influences Actual Usage for Toddler Nutrition Monitoring System.

$\mathrm{H}_{1}=$ Perceived Ease of Use has a positive effect on Actual Usage Toddler Nutrition Monitoring System.

In Table 11 the test statistic value (p) of $0.00, \mathrm{H}_{0}$ is rejected if the $\mathrm{p}$ value is less than the 0.05 significance level, then the conclusion of the Perceived Ease of Use hypothesis has a positive effect on Actual Usage of the Toddler Nutrition Monitoring System.

4. The Perceived Usefulness Hypothesis has a positive effect on the Actual Usage of the Toddler Nutrition Monitoring System

Assume,

$\mathrm{H}_{0}=$ Perceived Usefulness has a negative effect on Actual Usage for Toddler Nutrition Monitoring System.

$\mathrm{H}_{1}=$ Perceived Usefulness has a positive effect on Actual Usage Toddler Nutrition Monitoring System.

In Table 11 the test statistic value (p) of $0.00, \mathrm{H}_{0}$ is rejected if the $p$ value is less than the significance level of 0.05 then the conclusion of the Perceived Usefulness hypothesis has a positive effect on the Actual Usage of the Toddler Nutrition
Monitoring System.

5. The Attitude Toward Using Hypothesis has a positive effect on the Actual Usage of the Toddler Nutrition Monitoring System

Assume

$\mathrm{H}_{0}=$ Attitude Toward Using negatively influences Actual Usage for Toddler Nutrition Monitoring System.

$\mathrm{H}_{1}=$ Attitude Toward Using has a positive effect on Actual Usage Toddler Nutrition Monitoring System.

In Table 11 the test statistic value $(\mathrm{p})$ of $0.00, \mathrm{H}_{0}$ is rejected if the $\mathrm{p}$ value is less than the 0.05 significance level, then the conclusion of the Attitude Toward Using hypothesis has a positive effect on the Actual Usage of the Toddler Nutrition Monitoring System.

\section{CONCLUSION}

After doing research, the hypotheses prepared previously proved all, but in the Perceived Usefulness variable, it is necessary to increase the trust given to users of the Mozita Application, especially regarding the benefits that will be gained after routinely using this application.

The scope of research for further research can be expanded again, and the need for mobile applications is made to facilitate the operation of the Mozita Application.

\section{ACKNOWLEDGMENTS}

This work was supported by Master of Information System Diponegoro University.

\section{REFERENCES}

[1] Tulsi, R.B., dan Muniraj, C., 2013, Nutritional Status of Under Five Year Children and Factors Associated in Kapilvastu District, Nepal, Journal of Nutritional Health \& Food Science 1(1), 1-6, DOI: 10.15226/jnhfs.2013.00106.

[2] Alemneh, K., Dayanand, B., dan Yordanos, G., 2017, Factors Associated With Nutritional Status of UnderFive Children in Yirgalem Town, Southern Ethiopia, IOSR Journal of Nursing and Health Science, Volume 6 Issue 2 Ver. $\mathrm{V}, 78-84$.

[3] Riddhi, G., Sarmistha C., dan Suniti, G.C., 2016, A Study to Evaluate the Effect of Various Maternal Factors on the Nutritional Status of Under-Five Children, Indian Journal of Nutrition, Vol.3 Issue 2, 149.

[4] Bakr, A.M.A.E.B., Hasaneen, B.M., dan Bassiouni, D.A.H., 2018, Assessment of Nutritional Status in Children With Chronic Kidney Disease Using Hand Grip Strength Tool, Journal of Renal Nutrition, Volume 28 , Issue 4, Pages 265-269.

[5] Wilkinson, T.J., Richler-Potts, D., Nixon, D.G.D., Neale, J., dan Smith, A.C., 2019, Anthropometry-based Equations to Estimate Body Composition: A Suitable Alternative in Renal Transplant Recipients and Patients With Nondialysis Dependent Kidney Disease?, Journal of Renal Nutrition, Volume 29, Issue 1, Pages 16-23.

[6] Giles, J., dan Satriawan, E., 2015, Protecting child nutritional status in the aftermath of a financial crisis: Evidence from Indonesia, Journal of Development Economics, Volume 114, Pages 97-106.

[7] Sun, H., 2012, Understanding User Revisions When 
Using Information System Features: Adaptive System Use And Triggers, MIS Quarterly Vol. 36 No. 2 pp. 453478.

[8] Muliyana, Nuraeni, Suriana, Mardiana, A., Syafruddin, S., Suryani, A., Sharvianty, A., dan Andi, N.U., 2020, Midwives' perceptions about the ease of sisfor_bidanku application for toddler anthropometric-based growth and development, Enfermería Clínica, Volume 30, Supplement 4, Pages 539-543.

[9] Rahman, M.M., Lesch, M.F., Horrey, W.J., dan Strawderman, L., 2017, Assessing the utility of TAM, TPB, and UTAUT for advanced driver assistance systems, Accident Analysis \& Prevention, Volume 108, Pages 361-373.

[10] Fazil, A., Rupert, W., dan Ejaz, A., 2016, Investigating the influence of the most commonly used external variables of TAM on students' Perceived Ease of Use (PEOU) and Perceived Usefulness (PU) of e-portfolios, Computers in Human Behavior, Volume 63, Pages 7590.

[11] Tet, K.C, dan Noraidah, S., 2015, Utilitarian or Experiential? An Analysis of Usability Questionnaires,
International Journal of Computer Theory and Engineering, Vol. 7, No. 2.

[12] Melas, C.D., Zampetakis, L.A., Dimopoulou, A., dan Moustakis, V., 2011, Modeling the acceptance of clinical information systems among hospitalmedical staff: An extended TAM model, Journal of Biomedical Informatics, Volume 44, Issue 4, Pages 553-564

[13] Akhmad, M., Tomohiro, U., dan Katsumori, H., 2019, Capturing consumer value and clustering customer preferences in the Indonesian halal beef market, Meat Science, Volume 156 Pages 23-32.

[14] Robyn, L.R., Anjala, S.K., Pushkin, K., dan Pankaj, M., 2013, A combinatorial optimization based sample identification method for group comparisons, Journal of Business Research, Volume 66, Issue 9, Pages 12671271.

[15] Luiz, P.F., dan Patrícia B., 2019, Chapter 9: Hypotheses Tests, Data Science for Business and Decision Making, Pages 199-248.

[16] Bin, W., Ruodu, W., dan Yuming, W., 2019, Compatible matrices of Spearman's rank correlation, Statistics \& Probability Letters, Volume 151 Pages 67-72. 